8

\title{
Using a participator for teaching modern methodologies of business such as JIT, MRP and cellular organisation
}

T.A.J. Nicholson

London Business School

Sussex Place, Regent's Park

London NW1 4SA, UK

Telephone: (44) 1712625050

Tax: (44) 1717247875

email:anicholson@lbs.ac.uk

\begin{abstract}
The teaching of JIT, MRP or Cellular Manufacture rarely gets beyond the learning of the vocabulary of the ideas, the claimed advantages on offer and providing an awareness of some of the difficulties. Students - both on degree and executive courses - gain little idea of how to implement the methods and the disruption during transition which they will cause. Equally, going on a site visit where it is claimed that these methods are in use gets little beyond observation of a working practice.
\end{abstract}


The learning of the ideas can be transformed through gaining an experience of the process and the transition by participating in a practical, if miniature, situation. Far from being just a set of words describing a modern technique, the students are suddenly confronted with the challenge of making sense of the principles in practice and recognising the contextual attractions and difficulties as well as the cultural shock of trying to impose an idea on a set of people who have no knowledge of it. The responses from student bodies and organisations have been dramatic in terms of learning.

\section{Keywords \\ Participation, simulation, modern methods, JIT, Cellular, CIM}

\section{THE CHALLENGES IN EDUCATION FOR OPERATIONS MANAGEMENT}

The centre ground of the subject of Operations Management has shifted significantly over the last twenty years. Emerging from a history in Industrial Engineering and Operations Research, the subject took the new dimensions of modern methods (fundamentally influenced by Japan), the aspiration to influence strategy (in manufacturing strategy) and the analysis of services from an operational point of view. These new dimensions lifted the subject up to a new significance for teaching within business and for research within management. It rescued the subject from being an extension, often a poor relation, of the technology or engineering function to a subject linking the technology to commercial value. (Anderson, 1995)

However there was also a loss. Although the subject could be presented as new methods and best practice, its centre had moved outside the work place into becoming an ability to comment on the desirable features of the business and the possible modes for improvement Whereas original subject mater had lost its relevance to the future of the business, the new areas of study had lost their link back to the working in the current work place. The unsolved challenge in teaching Operations Management was how to represent the reality of the operations taking a business standpoint. Students of the subject had moved their stance: from being insiders with no view of commercial value, they had become outsiders with no awareness of the internal work.

Experience of the authors was that a gap was opening up between what was taught and researched and what was needed. Conducting extensive projects with student groups inside businesses, students were found to have very little idea about how to recognise the inside working of the business. Lacking a perception of the "here and now" working of the offices, departments and shop floor of a business the students on arriving and running a business operation, would typically polarise 
into one of two views: either the business operation could be run much better with modern methods or that the people working the operations had difficult, impossible jobs with little chance of success. The reality was that students of all ages had no idea how to analyse and perceive a working business operation. The educational and research material was enabling them to comment but not to manage or participate.

The answer to the problem was not simply more teaching of what a business operation is. The abstract description of operations is rather like examining the drawing of a skeleton when the lesson is on the live human being which is being discussed. To some extent the answer might lie in the field trips to working operations and the use of videos of working businesses to capture the relevance and challenge of running and managing the business. But even these approaches are time-consuming and can look simple. The learning can only be done in a participative manner.

Simulations and computer games permit a degree of participation at the individual or group level. The idea of an unfolding situation can be grasped, time pressures and the existence of choices on which judgements must be made. But simulations of the decision making lack the key aspect of reality: actually doing a physical task and, even more demandingly, the need to get a collection of other people to do the tasks. The management of operations, as distinct from the study of Operations Management, has to imply the transfer of a decision through the medium of systems, personnel and structure. The idea of experiment, and the risk and problems of communication are central.

The challenge of finding out a mode of learning is of course constrained by several factors. The construction of an exercise must involve a relatively short setup time. There is no case for having an educational experience which takes a long time to learn how to do it in order to do it. The whole learning package has to be complete within three hours including set-up, learning experience, discussion and conclusion.

A further challenge is to be able to develop a scheme which permits real choices to be experienced but which is still well within the control of the teacher or instructor. It must work with significant numbers of students, force students to do something specific as individuals but still allow the individuals to learn what the group result is. Perhaps the greatest short-coming in management education is the constraints of emerging students only as individuals, rather than in the reference frame of the social and technical groups which form the fundamentals of the complex businesses and the associated management challenge. 
Meeting these challenges has been the major aim of the work on Operations Management education at London Business School: "how to bring the management of operational reality into the classroom" in an efficient way.

The guiding experiences have been based on the work undertaken in smaller companies in putting in control and information systems to link the working practices to the commercial outcomes and the twin, if rather schizophrenic, task of educating managers to have a theory of what they do and telling students (and researchers) that there must be a "doing" of what they learn and think.

The next section will describe the initial system called Discovery I which fulfilled the above requirements and which then led on to the opportunity to extend it to the teaching of modern methodologies in a participative experimental manner.

\section{THE ORIGIN OF THE 'PARTICIPATOR': THE DISCOVERY I EXERCISE}

For the last five years we have used an exercise called Discovery I which fulfils the desired aims of engaging a student body in he Operations Management process. So successful has it been that it is now used throughout all courses as the means of explaining:

- the challenge of specifying the operational system

- the challenge of getting people to do their jobs, in accordance with a specification

- the question of how to evaluate a system and distinguish the commercial result, and the operational result

- the pressure on management to guess at improvements, negotiate approval for change and experiment with the action.

The basis of the whole scheme is apparently very simple. But by compressing time, by involving multiple people with no experience, and by using a computer driven real time system to record and monitor the events as they happen, the difficulty of making the system work is equivalent to the challenge of running an actual business situation. Nearly all the problems are present: physical product tolerance, progressing of orders through the system, confusion about quality, supply chains, commercial commitments and agreements. The scheme has been used extensively with managers in companies and many have remarked on how representative it is of the management challenge of operations as distinct from the technical challenge of operations.

The basic exercise lasts for three hours with half-an-hour's preliminary setup and description. The student (as management) body have to assemble one product to an incoming demand stream. As the work itself progresses through a series of ten steps each with its own specialism, each with its contribution to quality, delivery 
and cost, against a time driven requirement, the pressure to succeed is substantial. The whole scheme is monitored automatically by a system of telepads connected to a PC which in turn is connected to a large screen showing status continuously. The student body thus also get a glimpse of how a control system works in addition to the physical task, the working environment and the management process.

The aim of the learning is to demonstrate and test the process of continuous improvement which is so widely proclaimed as a desirable objective. However much of the real purpose is to learn how to specify a configuration of a working system and test it in action on the basis of the improvement process. The real time control scheme produces detailed analysis of what has happened. In effect it is possible to simulate the actual happenings in which the students have been involved. The dominant awareness in this exercise is to become aware of the cycle of how to fit people to a design of a system, how they are in effect testing that design, and how their efforts can be evaluated with a view to improvements of the original design. Rarely has continuous improvement been cast in this light.

\section{TEACHING MODERN METHODOLOGIES}

The success with the Discovery I exercise in creating an awareness of the challenges of specifying and improving an operational practice led on naturally to the review of its potential for introducing the modern methodologies such as JIT, CIM and Cellular Organisation, TQM etc. (Schonberger, 1988, Sepehri, 1988, Black, 1988) The virtue of moving on from the experience of Discovery I to the new method was that no basic learning would be necessary of the technical product characteristics or the basic construction skills. That being the case, it would immediately lead on to the fundamental questions of the exploration of the principles and the practical use of these systems. Four fundamental questions are:

- How can the principles of the proposed system ideally be translated into the practical realisation?

- How can the transition from the current situation be made at a physical configuration level?

- What different kinds of behaviour must be expected of the personnel and of the line itself, eg what kinds of discipline will be expected?

What can the new system (eg JIT) offer the existing company in terms of market potential, cost effectiveness and improvement in management processes.

In order to conduct this exercise with the right degree of commitment and the educational process was organised in terms of group competitiveness and relevance. The whole exercise was presented in terms of the realistic worry companies have of adopting new systems and the consultative process of consideration and method selection. There are four groups in total. One group was appointed as general consultants to the Discovery I manager (the teacher) and 
three other groups were appointed to represent technical suppliers of operational management "answers" JIT, CIM (embodying MRP) and Cellular team based systems. The overall format is shown in Table 1.

Table 1 Implementing Modern Methodologies in Practice - The Discovery II Exercise

Objective To apply the ideas of JIT, CIM and Cellular Systems to an existing business which has reached its limits

$\begin{array}{ll}\text { Method } & \text { Team 1 } \\ & \text { Team 2 } \\ \text { Team 3 } \\ \text { Team 4 }\end{array}$

Timetable Team 4 (15 mins)

Teams 1, 2, 3

Team 4

Propose JIT to Discovery I
"“ CIM to “" “"
“ Cellular to “" “"

Provide a basis for assessing the most successful proposal for delivery to Discover I management

State requirement for a breakthrough in

Discovery I

Organise a presentation (30 mins each) covering:

- The idea: its concept and framework

- The application: what form it takes in Discovery I

- The implementation: demonstrate what is required of the people, the disciplines, time controls

- The opportunities in the market

Appraise the results and award contract (30 mins)

The first critical point was the role of the general consultant as the appraiser of the offerings of the new methods as presented and tested. The emphasis of the appraisal had to consider how the new system proposed would help 'the company' Discovery Electronics break through beyond the limitations of continuous improvement and make the management task simpler. The second critical point was embodied in the fact that the group had to demonstrate the idea in practice on the Discovery Electronics system.

Each group was given some reading on the concept which they had to communicate. To maintain the pace of the learning they were provided in advance with a whole presentation on the scheme for which they had to sell it containing 
the provisional detail of layout for the purpose, jobs for the people to do and a flow and control system. They were thus in a strong position to succeed and be convincing in making the statements on technical purpose, organisational requirement and value of the method.

The pressure to succeed comes naturally from the group will to win. But winning required four fundamentals to be delivered:

- the achievement of more profit in the trial run

- the acceptance by the existing workers that they could run it

- the ease of management

- the pressure of future potential externally for a market and internally for flexibility.

To emphasise this last point the three different systems were introduced under the slogans:
JIT:
"let the trays do the work"
CIM:
"leave the stress to the computer"
Cellular:
"teamwork will win over all"

Each technical team had to display a bias and the appraisal group had to consider both the technical merit and the artistic impression in the decision of which scheme to adopt. Experience so far has suggested that any one of the schemes can become the winner of modern methodologies for Discovery Electronics to adopt which leaves the exercise open.

This exercise has been tested four times so far on student bodies from 30 to 50 in number in a three hour time span. The outcomes have given rise to the following experiences:

- an extensive agreement that the students would never have understood what JIT, CIM, or Cellular manufacture meant, without actually doing it or more precisely, trying it out

- an awareness of the difficulty of changing the mind set of the existing personnel. Repeatedly the students tried to copy their existing practices from Discovery I despite their having to take in those practices or a reason to fear change

- a surprise that there were different ways of organising the operation each of which had a unique but coherent set of requirements covering layout, people, flows and controls (Adler and Cole, 1993).

\section{$4 \quad$ RESULTS OF THE EXPERIMENTAL LEARNING}

The principal benefit of the learning of modern methodologies within the Discovery II environment has been the clarification of what these ideals and systems have meant "on the ground". They have answered the question "How 
would I recognise a JIT, CIM or Cellular system if I actually saw one?" - a problem not resolved by teaching the characteristics of the techniques as principles away from the practice.

Instead of considering that the systems will be an ideal and must be pushed to the limit of fulfilment, the learning through this scheme has emphasised the transitional nature of change, the implementation effort and the behavioural responses needed both on workers and managers. In this way the learning process has naturally incorporated the implementation questions as part of the education rather than as a separate piece of learning which needs subsequent consideration. (Research writing meanwhile has rather worryingly separated out the challenges of the principle and the implementation problems associated with making them work.) The proposal of the idea and its working practices thus become concurrent issues.

Thirdly the technique of the method had to be considered within the limits of existing technology, know-how and prospects for the business. The judgement of the success of the modern methodology is not simply based on how far it embraces the operations and takes over the business. It has to make its mark up to a point. For this reason, in this exercise, great stress was placed on the appraisal group and on how it distinctly instruments:

- the success of the business

- the success of the technique adopted as a technique

- the success of the adoption process

Failure on any of these dimensions needs to be distinguished. (Leonard-Barton, 1992)

Finally, the students as management groups were able to learn perhaps the most fundamental capability in operations:

- seeing how the system manages the operations and the manager manages the system, and thus achieves the ability "to manage complexity simply"

- recognising that management is continually conducting an experiment

The advantage of this real time learning scheme on the use of modern methodologies was that it provided a glimpse of the idea that the manager manages the model - the focused model of JIT, CIM or Cellular organisation - instead of managing the detail. The working practice had to be seen through the framework of the model and ideals as a means of managing greater complexity.

The initial conclusions therefore have provided a basis for a highly efficient mode of learning, in the "learning by doing" idea. We no longer have to teach the ideas derived from the application, derived from the implementation. They can all be 
taught as one and indeed different schemes can be compared. The opposing camps in the literature of the new technologists versus the behaviouralists can be recognised and debated "on-site" by the student bodies. The experience reintroduces the fundamental place of negotiation, risk-taking, and vision of operational detail which is so difficult if not impossible to capture in traditional teaching and learning modes.

\section{REFERENCES}

Adler, P.S. and Cole, R.E. (Spring 1993) Designed for Learning: A Tale of Two Auto Plants, Sloan Management Review, 85-93 Anderson, B. et al (1995) Engineering education on production management. Different levels and degrees in five European countries: a comparison Black, J.T. (1988) Cellular Manufacturing Systems, Just-in-Time Manufacture, ed C.A.Voss, IFS Publications Leonard-Barton, D. (Fall 1992) The Factory as a Learning Laboratory, Sloan Management Review, 23-38 Schonberger, R. J. (1988) The Kanban System, Just-in-Time Manufacture, ed C.A. Voss, IFS Publications Sepehri, M. (1988) Developing and implementing control systems for repetitive manufacturing, Just-in-Time Manufacture, ed C.A. Voss, IFS Publications

\section{BIOGRAPHY}

Following employment with IBM and the Atomic Energy Authority, he joined the London Business School in 1970. In 1974 Alastair Nicholson became Professor of Operations Management at London Business School. Since then he has worked jointly in education and with businesses on the management of operational systems. Professor Nicholson's principal interests lie in the matching of the management processes to the issues of business profitability and operational effectiveness. The work in this field has been developed with a wide variety of companies in the UK, Eastern Europe and the Far East, often on extended long term projects. 